\title{
Е.В. Брызгалина
}

\section{СОЦИАЛЬНЫЙ ЗАПРОС НА КРЕАТИВНОСТЬ В ПРОЦЕССАХ И (ИЛИ) В РЕЗУЛЬТАТАХ ОБРАЗОВАНИЯ: ЧТО ИМЕННО МОЖНО ИЗМЕРЯТЬ? ${ }^{1}$}

\begin{abstract}
Философское рассмотрение запроса на креативность в образовании требует определения сущчности креативности, выявления многообразия ее проявлений и дифференцированного понимания социального заказа на креативность. Субъекты, выступаюшие стейкхолдерами ориентации образования на креативность, формируют социальньй запрос, во-первых, на формирование как результата образования компетенции креативной личности и, во-вторых, запрос на создание креативной образовательной среды и использование в педагогическом прочессе креативных образовательных технологий.

Ключевые слова: креативность, философия образования, образование, сочиильный заказ, результат образования, прочесс образования, креативная образовательная среда.
\end{abstract}

Войдя в научный оборот в конце XX в. сначала в психологии, затем в педагогике и управленческих дисциплинах, понятие «креативность» не получило однозначного понимания. Общим местом концептуализации креативности стала констатация: современный сложный мир «требует людей, которые могут разрабатывать сложные творческие решения, с которыми сталкивается общество и образование» [1]. Обращение к анализу креативности возможно только при принятии исходной посылки о чрезвычайной сложности, о специфике образования как области проявления и формирования этого феномена, а также о зависимости результатов анализа от инструментов выявления и оценивания субъектов запроса на креативное образование, от способов измерения компетенций, связанных с креативностью, обретенных по факту получения образования.

Оценка места креативности в образовательной политике неоднозначна. Одновременно подчеркиваются: 1) роль образования в формировании креативности как ключевой компетенции XXI в.; 2) снижение творческого потенциала по мере прохождения через систему образования [2] в растущей стандартизации образования.

Следует согласиться с Д.Н. Боровинской в том, что ситуация «несрабатывания» традиционных способов и средств действия для индивидуальных и коллективных субъектов имеет место в современном обществе. Пространство поступка через личностный выбор при невозможности ориентироваться на традиционные алгоритмы быстро расширяется в основном за счет прогресса технонауки, меняющей взаимоотношения между познанием и преобразованием реальности. Однако представляется важным не придавать креативности статус единственного гаранта благополучия и безопасности общества. Кон-

${ }^{1}$ Статья подготовлена в рамках деятельности ведущей научной школы МГУ им. М.В. Ломоносова «Трансформации культуры, общества и истории: философско-теоретическое осмысление». 
сервативная воспроизводимость ценностных матриц культуры и нормативности социальных институтов также является фактором благополучия и безопасности общества. Таким образом, проблематика соотношения традиционности и инновационности при рассмотрении социального прогресса обладает нарастающей актуальностью, для фиксации которой обращение к задаче выявления субъектов, заинтересованных в ориентации образования на креативность, весьма значимо.

Философское рассмотрение креативности в образовании, в отличие от частно-научных дискурсов, требует определения сущности креативности, выявления многообразия ее проявлений, и с учетом этого фиксации ее места в образовании, понятом как ценность, как процесс, как система и как результат. Применительно к дискуссии об измеримости социального запроса представляется, что именно такое понимание образования позволяет выявить тех субъектов, которые, выступая стейкхолдерами креативного образования, могут формировать и реализовывать социальный запрос. Аспектное понимание образования соотносимо с трактовками креативности как характеристики личности, как процесса и как продукта [3]. Если понимать под социальным заказом на креативность некие ожидания от системы образования в виде компетентностных результатов обученного лица, то скорее следует говорить о множестве социальных заказов от различных стейкхолдеров. Идеальная ситуация совпадения у различных стейкхолдеров сути и направленности запроса на креативность, сформированного вне образования как системы, труднопредставима в современном обществе. И причиной этого являются скорее не понятийные расхождения, а ценностные различия [4]. Образовательные субъекты способны в рамках образования, понятого как система и как процесс, формировать креативность как результат образования, посредством акцентуации собственной деятельности при образовательных взаимодействиях. Вопрос в том, как соотносятся в такой деятельности внешние факторы развития образования (тот самый социальный заказ) и внутренняя логика образовательного процесса в конкретной образовательной среде, ориентированной на определенные концептуальные установки. При реализации запроса на креативность субъекты могут ориентироваться на различное понимание креативности, выделять как значимые несовпадающие характеристики креативности, исходить из несовпадающих трактовок места креативности в ценностном, процессуальном, системном и результативных аспектах образования. Кроме того, субъекты образования могут деятельностно ориентироваться на креативность, но результат их усилий может не совпасть с социальными ожиданиями в силу зазора между целевыми образовательными установками и образовательным результатом и оказаться тем самым невостребованным. Поскольку взаимодействия между средой и обучающимся являются самоорганизующимися и динамичными, субъекты образования не обладают возможностью такого управления образовательным процессом, при котором обеспечивается обязательное и полное превращение возможности в действительность - воплощение заказа на креативность в качественных характеристиках обученного лица. Указанные несовпадения и противоречия как на уровне целеполагания, так и на уровне процесса и результата образования создают весьма сложное для исследования пространство результатов образования как ответа на социальный заказ. 
Обратим внимание на то, что, возможно, социальный заказ на креативность стоит дифференцировать, т.е. выделять как минимум две стороны социального запроса на креативность в зависимости от их адресованности к различным аспектам образования: запрос на креативность как результат образования и запрос на креативность собственно процесса образования.

Выделение запроса на креативность как результат образования, очевидно, связано с нарастающим динамизмом общества (об этом Д.Н. Боровинская подробно говорит, описывая субъекта-носителя креативности как результат образования). Социальный заказ на креативность как результат образования значим в системе компетентностных результатов для успешности в творческих профессиях, создании инновационных продуктов, готовности к реализации установки на образование в течение жизни и т.д. В этом смысле конечной целью современной образовательной системы должно быть развитие независимых и свободных людей, которые в процессе удовлетворения собственных потребностей развивают общество, где креативность является основой для развития. Отметим как дискуссионную тему возможность создания массовых и стандартизированных инструментов определения степени сформированности креативных компетенций [5]. Результаты образования в части сформированности тех качеств личности, которые могут быть связаны с креативностью (оговорюсь еще раз, при условии существования различных интерпретаций креативности), не могут быть отражены в виде нормальной кривой распределения измеримых результатов, при которой большинство проявлений имеют «нормальную», т.е. «умеренную», степень новизны. Скорее, следует ожидать, что значительная часть результатов измерения креативности окажется тяготеющей к низким параметрам, в то время как у некоторых субъектов степень проявленности признаков креативности будет высокой. Соответственно, запрос на проявление креативности по факту прохождения ступеней образования не может быть связан с ожиданием некоего базового уровня креативности, достигнутого всеми обученными субъектами. Речь может идти лишь о создании условий для того, чтобы по факту образования повысить ценность креативных моментов любой деятельности для значимой части общества. Во всех случаях крайне затруднительно вычленить вклад в образовательные результаты со стороны отдельных субъектов образования и образовательных институций. Кроме того, социальный заказ на креативность не может установить требования к сознательным и бессознательным аспектам творчества. Обращаясь к взаимосвязи этих аспектов, важно отметить, что рассмотрение творчества как целенаправленного процесса, а образования как целенаправленного его развития не означает, что все аспекты творчества полностью сознательны и преднамеренны. Однозначное приписывание сугубо позитивной социальной коннотации креативности как результату образования было бы упрощением. Повышение уровня креативности личности, будучи сопряженным с нарастанием эмоционально-личностных нонконформных проявлений проблемного восприятия мира, для ряда социальных субъектов воспринимается как негативный продукт реализации установки на креативность образования, причем продукт не побочный, а обусловленный самой целевой установкой повышения уровня креативности.

С другой стороны, Д.Н. Боровинская рассматривает креативность как естественную деятельную способность мышления субъекта образовательного 
процесса, реализация которой направлена на преодоление «ситуации разрыва», на решение задач, для которых не срабатывают традиционные способы и средства. Продолжим мысль автора в отношении запроса на креативность процесса образования. Этот процесс сам может быть рассмотрен как самоценный аспект образования. Например, в системе школьного образования принятие этой установки влечет за собой активный поиск конкретных направлений и форм изменения процесса образования в пользу возможности задавать вопросы, решать открытые задачи с множеством допустимых ответов, устанавливать связи, оценивать альтернативы, критически осмыслять идеи, действия и результаты с позиции ответственности. Социальный запрос на формирование креативной образовательной среды, широкое использование в педагогическом процессе креативных форм и технологий также представлены множеством стейкхолдеров. В этом случае востребованы такие характеристики образовательного процесса, которые создают условия для развития потенциала тех, кто учится, и тех, кто учит [6]; повышают вовлеченность, образуют креативную образовательную среду в образовательных организациях и при выходе образования в открытое социокультурное пространство, поддерживают мотивацию к постоянному творчеству в процессе образования для всех образовательных субъектов. Таким образом, каждая из отмеченных характеристик требует измерения, а запрос на включение креативности в процесс образования оказывается сложноизмеримым в силу множественности проявлений креативности в процессе образования.

Креативная личность и креативный продукт формируют друг друга через непрерывные трансакции в процессе образования в креативной среде. Создание качественной среды, способствующей развитию креативности, не является итоговой целевой установкой, а лишь инструментом и контекстом, условием и фактором творчества субъектов образовательного процесса. Как ни парадоксально звучит, но креативность образовательного процесса должна стать рутинной практикой образования по различным дисциплинами на разных уровнях образования. Проявление этого - многочисленные публикации о конкретных креативных педагогических технологиях в профильных международных журналах: «Creative Education», «Thinking Skills and Creativity», «American Journal of Creative Education».

Готовность к трансформации образовательного процесса в направлении ухода от стандартизированного воспроизведения готового знания связана с позицией и личностью педагога как ключевого субъекта, который должен выступать одновременно в роли заказчика и актора креативного процесса образования. Однако креативность относится к психологическим характеристикам личности, которые не входят в перечень требований к профессиональной пригодности преподавателей [7]. В силу этого ориентация на креативность в деятельности образовательных субъектов не зависит напрямую от институционального закрепления социального заказа на креативность в системе образования.

Отдельную проблему составляет определение связанности креативности процесса образования с качеством образования. Несовпадение критериев качества образования, внешних по отношению к образованию и внутренних усложняют и без того сложную картину. 
Структура управления системой образования в целом и образовательными организациями как ее элементами для реализации социального заказа на креативность должна найти механизмы встраивания креативности в стандарты, регулирующие условия образовательного процесса требования к педагогу и задающие ожидаемые результаты образования. Возможно, сама система управления должна обладать большей пластичностью при моделировании педагогических взаимодействий и результатов образования. Направленность и формы управленческих воздействий на систему образования сами нуждаются в креативном компоненте, соотношение которого с традиционными компонентами нуждается в дополнительном пояснении.

\section{Лumepamypa}

1. Thurlings M., Evers A.T., Vermeulen M. Toward a model of explaining teachers' innovative behavior: A literature review // Review of Educational Research. 2015. № 85. P. 430-471

2. Robinson K., Lee J. R. Out of our minds. Tantor Media, Incorporated, 2011.

3. Раренко A.A. К вопросу о креативности и способах ее изучения и измерения // Социальные и гуманитарные науки. Отечественная и зарубежная литература. Сер. 11: Социология: Реферативный журнал. 2020. № 3. С. 93-103.

4. Мелик-Гайказян И.В., Мелик-Гайказян М.В. Минерва и Янус: символы поклонения визуальным эффектам современного образования // ПРАЕНМА. Проблемы визуальной семиотики. 2019. № 4. C. $172-193$.

5. Бальхина Т.М., Нетёсина М.С. Креативное образование и креативное тестирование // Полилингвиальность и транскультурные практики. 2014. № 4. С. 7-12.

6. Червонный М.А. Контекст педагогического образования // ПРАЕНМА. Проблемы визуальной семиотики. 2019. № 4. С. 206-222.

7. Медведь А.А., Медведь П.А., Миэринь Л.А. Институциональная готовность системы образования РФ к переходу на технологии креативного образования // Известия СПбГЭУ. 2018. № 4 (112). C. 121-126.

Elena V. Bryzgalina, Lomonosov Moscow State University (Moscow, Russian Federation).

E-mail: evbrz@yandex.ru

Vestnik Tomskogo gosudarstvennogo universiteta. Filosofiya. Sotsiologiya. Politologiya - Tomsk State University Journal of Philosophy, Sociology and Political Science. 2020. 58. pp. 272-277.

DOI: $10.17223 / 1998863 \mathrm{X} / 58 / 25$

SOCIAL DEMAND FOR CREATIVITY IN THE PROCESSES AND (OR) IN THE RESULTS OF EDUCATIONAL PLANNING: WHAT CAN BE MEASURED?

Keywords: creativity; philosophy of education; education; social demand; result of education; educational process; creative educational environment.

A philosophical view of the demand for creativity in education requires the definition and consideration of the diversity of creativity, as well as a differentiated understanding of the social demand for creativity. Interested in orienting education towards creativity stakeholders form social demand for the formation of the competence of a creative person as a result of education and for the formation of a creative educational environment and the use of creative educational technologies in the pedagogical process.

\section{References}

1. Thurlings, M., Evers, A. T. \& Vermeulen, M. (2015) Toward a model of explaining teachers' innovative behavior: A literature review. Review of Educational Research. 85. pp. 430-471. DOI: $10.3102 / 0034654314557949$

2. Robinson, K. \& Lee, J.R. (2011) Out of our minds. Tantor Media, Incorporated.

3. Rarenko, A.A. (2020) What is creativity and how to study and measure it. Sotsial'nye i gumanitarnye nauki. Otechestvennaya i zarubezhnaya literatura. Ser. 11: Sotsiologiya - Social Sciences and Humanities. Domestic and Foreign Literature. Series 11: Sociology. 3. pp. 93-103. (In Russian). DOI: $10.31249 / \mathrm{rsoc} / 2020.03 .06$ 
4. Melik-Gaykazyan, I.V. \& Melik-Gaykazyan, M.V. (2019) Minerva and Janus: symbols of

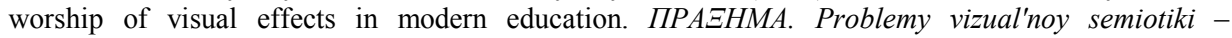
ПРАЕHМА. Journal of Visual Semiotics. 4. pp. 172-193. (In Russian). DOI: 10.23951/2312-78992019-4-172-193

5. Balykhina, T.M. \& Netesina, M.S. (2014) Creative education and creative testing. Polilingvial'nost' i transkul'turnye praktiki - Polylinguality and Transcultural Practices. 4. pp. 7-12. (In Russian).

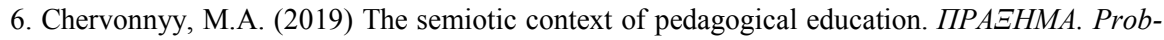

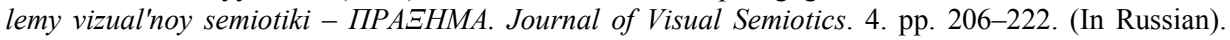
DOI: $10.23951 / 2312-7899-2019-4-206-222$

7. Medved, A.A., Medved, P.A. \& Mierin, L.A. (2018) Institutional readiness of the education system of the Russian Federation to the transition on the technology of creative education. Izvestiya SPbGEU. 4(112).pp. 121-126. (In Russian). 